\title{
SURGICAL TREATMENT OF TUMORS OF THE LACRIMAL GLAND BY CORONAL APPROACH
}

\author{
Tonchev T. \\ Medical University Varna, Faculty of Dental Medicine, Department of Oral and Maxillofacial \\ Surgery \\ Reviewed by: Assoc. Prof. V. Svestarov, MD, PhD
}

\begin{abstract}
The purpose of this research is examination of the clinical characteristics, the preparation and the course of the operative treatment of the tumors of the lacrimal gland. The following article presents four cases where a lateral orbitotomy with coronal approach is used. A complete excision of the tumor is conducted. The postoperative observation of the diseased varies between 18 and 114 months, and includes an analysis of the results.
\end{abstract}

Keywords: lacrimal gland tumors, orbital tumors, coronal approach, lateral orbitotomy

\section{BACKGROUND}

The tumors of the lacrimal gland are relatively rarely found and are mostly benign. As a whole they represent $9 \%$ from all orbital processes (1). The diseases of the lacrimal gland are divided into inflammatory and lymphoid, followed by the metastatic processes and the primary epithelial tumors $(2 ; 3)$. Primary epithelial lacrimal gland tumors are histologically similar to those arising in the salivary glands. The pleomorphic adenoma and adenoid cystic carcinoma are the most common benign and malignant tumors, respectively $(4 ; 5)$. Given the low frequency of these tumors many publications offer a description of single cases and only a few consider larger groups of patients, observed for a longer period of time (6). The purpose of this study is the examination of the clinical features, the preoperative diag- nosis and preparations, the operative treatment and the following postoperative period when treating these tumors.

Tab. 1. Anamnestic and paraclinical data in the four cases (R - Right; L - Left; CT - computer tomography; $M R I$ - magnetic resonance imaging)

\begin{tabular}{||c|c|c|c|c|c||}
\hline \hline № & Gender & Age & $\begin{array}{c}\text { Complaints } \\
\text { (months) }\end{array}$ & Side & Investigations \\
\hline 1. & $\mathrm{~F}$ & 51 & 12 & $\mathrm{~L}$ & $\mathrm{CT}$ \\
\hline 2. & $\mathrm{~F}$ & 51 & 5 & $\mathrm{R}$ & $\mathrm{CT}$ \\
\hline 3. & $\mathrm{~F}$ & 72 & 10 & $\mathrm{R}$ & $\mathrm{CT}$ \\
\hline 4. & $\mathrm{M}$ & 62 & 8 & $\mathrm{R}$ & $\mathrm{CT} ; \mathrm{MRI}$ \\
\hline \hline
\end{tabular}

Tab. 2 Clinical data in the four cases (-/+ - anamnesis/examination; ACa - adenocarcinoma; NHL - non-Hodgkin lymphoma; PA - pleomorphic adenoma)

\begin{tabular}{|c|c|c|c|c|c|c|c|c|}
\hline \multirow{2}{*}{ № } & \multirow{2}{*}{ Exophtalmy } & \multicolumn{2}{|c|}{ Diplopia } & \multirow{2}{*}{$\begin{array}{l}\text { Size } \\
\text { Mм }\end{array}$} & \multirow{2}{*}{ Treatment } & \multirow{2}{*}{ Diagnosis } & \multirow{2}{*}{$\begin{array}{c}\text { Observation } \\
\text { (months) }\end{array}$} & \multirow{2}{*}{ Reoccurence } \\
\hline & & Anamnestic & Examination & & & & & \\
\hline 1. & + & - & + & $26 \times 13$ & Extirpation & $\mathrm{ACa}$ & 114 & No \\
\hline 2. & + & $-/+$ & + & $40 \times 35$ & Extirpation & NHL & 56 & No \\
\hline 3. & + & $-/+$ & + & $30 \times 25$ & Extirpation & PA & 43 & No \\
\hline 4. & + & - & + & $25 \times 20$ & Extirpation & PA & 18 & No \\
\hline
\end{tabular}

\section{Address for correspondence:}

Tsvetan Tonchev, Medical University Varna, Faculty of Dental Medicine, Department of OMFS, 55 Marin Drinov st., 9002 Varna, BULGARIA

E-mail: mfstonchev@mu-varna.bg; mfstonchev@mail.bg

\section{MATERIAL AND METHODS}

In the period 1998-2006 in the Department of Maxillofacial surgery of Naval Hospital -Varna have been operatively treated 4 diseased with tumor of the lacrimal gland. Based 
on the hospital's documentation the author performs an analysis of the data divided in: gender, age, the beginning of the disease, the side of the gland and the type of imaging study (tab. 1). The clinical symptoms, the size of the tumor, the operative treatment and histological diagnosis, as well as the term of postoperative observation and the discovery of reoccurrence can be found in tab.2. Exophtalmometric study has been made using the Hertel method. The given data is anamnestic. The sign (-) marks the lack of diplopia, the sign $(-/+)$ marks cases in which diplopia occurs only on superior and lateral gaze, $(+)$ marks the presence of diplopia.

\section{RESULTS}

The average age of the patients operated is 59 years, (between 51 and 72) - three women and a man. The period marking the beginning of the disease until hospitalization is between 5 and 12 months ( 8.75 in average). For first sign of the disease we accept the moment in which the patient realizes the presence of a problem and seeks medical help. In three of the cases the process engages the right lacrimal gland, and in one case - the left. The imaging studies include mainly $\mathrm{CT}$, and in one case MRI. In all four cases we determine well limited tumor formations with benign CT characteristics, with no data for infiltration of the surrounding structures. The preoperative exam shows marked proptosis in all 4 patients. The diplopia was analyzed as anamnestic data and at the same time a clinical exam was conducted for the discovery of hidden diplopia. The anamnesis accented on the occurrence of double vision in everyday duties. The result from the clinical examination showed manifested diplopia in all 4 patients. The operative treatment in all four cases included total extirpation of the tumor. This was conducted trough lateral orbitotomy where the access was secured with a coronal approach. Tab. 2 shows the dimensions of the tumor in each case. The size of the tumor after removal varies between $8 \mathrm{~cm}^{3}$ and $21 \mathrm{~cm}^{3}$. The postoperative treatment includes observation by an ophthalmologist and a maxillofacial surgeon and, in the case № 2 - a hematologist to determine the postoperative treatment concerning the leading disease. The surgical treatment was thorough in the other 3 cases. The postoperative observation was between 18 and 114 months (57.75 months average). During the whole period of observation no sign for reoccurrence of the disease was found in all four cases.

\section{DISCUSSION}

The lacrimal gland is divided by the orbital septum into two parts: palpebral which is superficial and orbital which is deeply situated. The tumors of the lacrimal gland most often originate from the deeper part, which is the reason for the late diagnostic, and to be accurate- the period when disturbances of the eyesight appear or there is a facial asym- metry and aesthetics (7). Most of the tumors of the lacrimal gland are benign and from them the pleomorphic adenoma is most frequent. The ratio is the same as with the tumors of the salivary glands $(2 ; 4 ; 8)$. Clinically they appear as well limited, slowly growing, painless swelling, which in the beginning leads to deformation of the upper external quadrant of the orbit and as a result leads to ptosis of the upper eyelid, exophthalmia, decreased mobility of the eyeball and diplopia. Possible impairment of vision is common. Two of the patients are diagnosed with these symptoms. The malignant transformation of the pleomorphic adenoma is possible in long term cases or when the excision of the tumor was not radical enough and there have been conducted more than one operation. Some authors recommend an operative treatment by excising the tumor after diagnosing it, excluding the biopsy $(3 ; 9)$. For preoperative diagnostics fine needle biopsy can be used as minimally invasive and informative method, enough to precise the surgical treatment. In the present cases this method did not give the information required, which can be explained with the lack of experience with the conduction of the technique and interpretation of the result.

In cases of malignant tumors of the lacrimal gland the adenocystic carcinoma is most common, followed by the adenocarcinoma. The surgical treatment of malignant tumors with such localization is still very discussible. According to some authors there is no substantial difference in the life expectancy when the capacity of the operation is increased. In confirmation of this fact we give the case in which the tumor was removed together with the orbital part of the gland, and the result was ten years outlive and lack of reoccurrence.

Almost 25\% of non-Hodjkin lymphomas are with extra nodal localization from which 3\% develop in the head and neck region (12). The tumor is in 5-14\% with orbital localization and is the most frequent primarily malignant tumor of the orbit (13). The tumor most commonly originates from MALT (mucosa-associated lymphoid tissue) cells or from the germinal centers of the lymph nodules. In principle the orbital localization of non-Hodjkin lymphoma is distinguished by slowly growing formation in the orbital area and the periorbital tissues. Choice of treatment is chemotherapy and radiotherapy. Between 50 and $80 \%$ of the patients are in total remission (14). Typical feature of the orbital surgery when treating non-Hodjkin lymphoma is not so much the radicalism of the operative method as the aspiration for providing enough tissue for histological and immunehistochemical test for the purpose of exact typification and a following chemotherapeutic treatment (15). In the present case the tumor was a non Hodjkin lymphoma connected to the gland and with a volume of 21 $\mathrm{cm}^{3}$. With the average size of the orbit around $30 \mathrm{~cm}^{3}$ this represents around $2 / 3$ of the capacity of the orbit (5). The patient was in full remission for 56 months after a course of chemotherapy. The recovery of the anatomical and functional integrity of the operated orbit was complete, with no disturbances or deficit. 


\section{CONCLUSIONS}

The diagnosis and the operative treatment of the tumors of the lacrimal gland require serious knowledge of the pathology of the orbit and is subject of interdisciplinary partnership. The leading role of the ophthalmologist demands early conduction of imaging study in all cases of asymmetry in the area or deficit in the mobility of the eyeball reported by the patient or determined during examination. The interpretation of the data based on the imaging studies requires participation of specialists in orbital surgery. The decision for operative treatment should be based on a thorough analysis of the clinical and preclinical facts and should be individual. The results from the operative treatment correlate to the biology of the tumor, the level of the preoperative diagnosis, the type of the operation and the possibilities of following treatment if necessary.

\section{REFERENCES}

1. Shields J, Shields C, Scartozzi R. Survey of 1264 patients with orbital tumors and simulating lesions: Ophthalmology 2004; 111: 997-1008.

2. Font R, Shannon LS, Bryan RG. Malignant epithelial tumors of the lacrimal glands. A

clinicopathologic study of 21 cases. Arch Ophthalmol; 1998;116:613-6.

3. Paulino A, Huvos A G. Epithelial tumors of the lacrimal glands: a clinicopathologic study. Ann Diagn Pathol ; 1999;3:199 -204.

4. Chuo N, Ping-Kuan K, Dryja TP. Histopathological classification of 272 primary epithelial tumors of the lacrimal gland. Chin Med $J ; 1992 ; 6: 481-5$.

5. Rootman J, Steward B, Goldberg R, et al: Orbital surgery: a conceptual approach. Philadelphia, Lippincott-Raven Publisher, 1995; pp. 75; 79.
6. Esmaeli B, Ahmadi MA, Youssef A, et al. Outcomes in patients with adenoid cystic carcinoma of the lacrimal gland. Ophthal Plast Reconstr Surg, 2004; 20: 22- 6 .

7. Perez D, Pires F, Almeida O, Kowalski L. Epithelial lacrimal gland tumors: a clinicopathological study of 18 cases. Otolaryngol Head Neck Surg. 2006 Feb;134(2):321-5.

8. Wright J, Rose G, Garner A. Primary malignant neoplasms of the lacrimal gland. Br J Ophthalmol 1992; 76: 401-7.

9. Chandrasekhar J, Farr D, Whear N. Pleomorphic adenoma of the lacrimal gland: case report. Br J Oral Maxillofac Surg 2001; 39: 390 -3.

10. Sturgis C, Silverman J, Kennerdell J, et al. Fine-needle aspiration for the diagnosis of primary epithelial tumors of the lacrimal gland and ocular adnexa. Diagn Cytopathol 2001; 24: 86 -9.

11. Polito E, Leccisotti A. Epithelial malignancies of the lacrimal gland: survival rates after extensive and conservative therapy. Ann Ophthalmol 1993; 25: 422-26.

12. Skarin A, Diagnosis in oncology. Unusual sites of malignancy. J Clin Oncol 2001; 19: 1570-1575.

13. Hohn J, Suh C, Lee S, Yang W: Primary lymphoma of the eye. Yonsei Med J 1998; 39: 196-201.

14. Hitchcock S, Ng AK, Fisher D, Silver B, Bernardo M, Dorfman D, Mauch P: Treatment outcome of mucosa-associated lymphoid tissue/marginal zone non-Hodgkin's lymphoma. Int J Radiat Biol Phys 2002; 52: 1058-1066.

15. Wanyura H, Uliasz M, Kaminski A, Samolczyk-Wanyura D, Smolarz- Wojnowska A. Diagnostic difficulties and treatment of non-Hodgkin lymphoma of the orbit. J Craniomaxillofac Surg. 2007 Jan; 35(1): 39-47. 